\title{
ANALISIS SEKTOR BASIS DAN USAHATANI IKAN AIR TAWAR SEBAGAI KOMODITAS UNGGULAN DI KECAMATAN PAGELARAN KABUPATEN PRINGSEWU
}

\author{
(The Analysis of Base Sector and Freshwater Fish Farming as a Main Commodity in Pagelaran Subdistrict \\ of Pringsewu Regency)
}

Brilian Patar Novenda Manalu, Muhammad Irfan Affandi, Teguh Endaryanto

Jurusan Agribisnis, Fakultas Pertanian, Universitas Lampung, Jl. Prof. Dr. Soemantri Brodjonegoro No. 1 Bandar Lampung 35145, Telp. 085380359133, e-mail: brilianpatarnovendamanalu@ gmail.com

\begin{abstract}
This research aims to analyze the base commodity and income levels of freshwater fish farmers. The research is conducted by survey method in which location was chosen purposively at Pagelaran and Lugusari Villages, Pagelaran Subdistrict of Pringsewu Regency with consideration that the location are the central of freshwater fish production (minapolitan areas). The samples are 44 freshwater fish farmers who are members of fish farmers group with farming experience of more than five years. The data was collected in June to July 2017 and is analyzed by Location Quotient (LQ) analysis to determine base commodity and fish farming analysis to identify income level of freshwater fish farmers. The result of $L Q$ analysis and fish farming analysis showed that the main base commodity was goldfish with $L Q$ score 1,18 and the highest income level from three business focus (breeding business, enlargement business, also the breeding and enlargement business of goldfish) was an enlargement business of goldfish with an income value of Rp1,556,440.29/1,000 m2/month.
\end{abstract}

Key words: base sector, freshwater fish, goldfish, income, main commodity

\section{PENDAHULUAN}

Subsektor perikanan adalah salah satu subsektor yang berpengaruh bagi perekonomian Indonesia. Subsektor perikanan menempati posisi kedua dengan kontribusi sebesar 24 persen setelah subsektor tanaman pangan dengan kontribusi sebesar 46 persen. Provinsi Lampung memiliki luas lahan tambak sebesar 37.985 hektare dan menempati posisi kedua di Sumatera, luas lahan kolam sebesar 13.751 hektare dan menempati posisi pertama di Sumatera, luas lahan karamba sebesar 174 hektare dan menempati posisi pertama di Sumatera, luas lahan jaring apung sebesar 321 hektare dan menempati posisi pertama di Sumatera, luas lahan mina padi (sawah) sebesar 161 hektare dan menempati posisi keenam di Sumatera. Potensi tersebut tentunya semakin memperkuat bahwa Provinsi Lampung adalah salah satu daerah minapolitan atau penghasil perikanan yang unggul. (Badan Pusat Statistik 2016).

Menurut Dinas Kelautan dan Perikanan Provinsi Lampung (2016), Kabupaten Pringsewu menempati posisi kelima atas potensi luas lahan perikanan dengan luasan sebesar 1.064,60 hektare. Sementara untuk produksi dan persentase produksi terhadap produksi total, Kabupaten Pringsewu 134 menempati posisi kedua setelah Kabupaten Lampung Tengah di posisi pertama. Pencapaian Kabupaten Pringsewu di posisi kedua merupakan salah satu prestasi, karena luas lahan yang dimiliki Kabupaten Pringsewu lebih kecil bila dibandingkan dengan kabupaten lain yang memiliki luas lahan yang lebih besar, sementara produksi lebih rendah dari Kabupaten Pringsewu. Berdasarkan persentase produksi Kabupaten Pringsewu menempati posisi kedua dengan persentase 14,02 persen setelah Kabupaten Lampung Tengah dengan persentase 28,92 persen. Subsektor perikanan memiliki peran yang penting dalam penerimaan PDRB sektor pertanian di Kabupaten Pringsewu. Subsektor perikanan menempati posisi kedua dalam kontribusi terhadap PDRB sektor pertanian dengan persentase sumbangan sebesar 22 Persen (BPS Kabupaten Pringsewu 2016).

Kabupaten Pringsewu adalah kabupaten dengan sembilan kecamatan yang memiliki potensi pertanian yang terbilang baik. Salah satunya adalah usaha perikanan air tawar yang digemari masyarakat Pringsewu. Kecamatan Pagelaran adalah kecamatan yang memiliki potensi luas lahan terbesar, yaitu 581,50 hektare. Potensi lahan tersebut baru termanfaatkan sebesar 305,25 hektare atau sebesar 52,50 persen. Berdasarkan nilai 
tersebut, maka masih terdapat 43,50 persen atau 276,25 hektare lahan potensial yang belum termanfaatkan dengan semestinya (Dinas Peternakan dan Perikanan Kabupaten Pringsewu 2016).

Budidaya yang dijalankan di Kecamatan Pagelaran terdiri dari pembibitan dan pembesaran ikan air tawar saja, sedangkan untuk pengolahan belum ada yang mengusahakannya. Yuwani, Irham, dan Jamhari (2014), menyatakan bahwa berdasarkan penelitiannya mengenai usaha pembenihan dan pembesaran ikan air tawar di Sleman, jenis usaha pembenihan adalah usaha yang paling menguntungkan bila dibandingkan dengan pembesaran. Hal ini dikarenakan pada tahapan pembenihan sekitar 80 persen modal hanya digunakan untuk biaya pakan saja sementara 20 persen digunakan untuk biaya operasional lainnya. Selain itu, pada usaha pembenihan ini jangka waktu hingga bibit ikan siap dijual hanya 25-30 hari saja, sementara usaha pembesaran memerlukan waktu minimal tiga bulan.

Harga adalah masalah lain yang dihadapi oleh petani ikan air tawar di Kecamatan Pagelaran. Harga ikan air tawar akan cenderung tidak stabil apabila musim panen raya tiba dan bersamaan dengan panen raya daerah penghasil ikan lain, seperti Jawa Barat dan beberapa kabupaten di Provinsi Lampung. Kondisi ini tentunya berdampak pada penurunan pendapatan petani akibat harga jual turun. Subyek pada penelitian ini adalah pembudidaya ikan air tawar yang tergabung dalam Pokdakan (Kelompok Pembudidaya Ikan) yang masih aktif dan berkelanjutan (continue) dalam menjalankan budidaya ikan air tawar. Berdasarkan latar belakang tersebut, maka penelitian ini bertujuan untuk menganalisis sektor basis, dan menganalisis tingkat pendapatan usahatani ikan air tawar di Kecamatan Pagelaran, Kabupaten Pringsewu.

\section{METODE PENELITIAN}

Metode yang digunakan dalam penelitian ini adalah metode survei. Pemilihan lokasi penelitian dilakukan secara sengaja (purposive) dengan pertimbangan bahwa Kabupaten Pringsewu memiliki urutan tertinggi kedua dalam hal tingkat produksi ikan air tawar (ikan mas, lele, gurami, patin dan nila) setelah Kabupaten Lampung Tengah. Kecamatan Pagelaran diambil secara sengaja dengan pertimbangan bahwa kecamatan ini merupakan kawasan minapolitan ikan air tawar di Kabupaten Pringsewu.
Responden diambil dari tujuh Pokdakan yang terdiri dari satu Pokdakan pembenihan (Desa Pagelaran), tiga Pokdakan pembesaran (satu Desa Pagelaran dan dua Desa Lugusari), serta tiga Pokdakan pembenihan dan pembesaran (dua Desa Pagelaran dan satu Desa Lugusari). Responden yang dipilih berasal dari unsur pengurus inti dan anggota Pokdakan dengan total petani sebanyak 103 orang. Sebaran responden petani ikan air tawar di Kecamatan Pagelaran, Kabupaten Pringsewu dapat dilihat pada Tabel 1.

Penentuan jumlah sampel menggunakan rumus yang dikutip dari Sugiarto, Sunaryanto, dan Oetomo (2003), yaitu :

$\mathrm{n}=\frac{\mathrm{NZ}^{2} \mathrm{~S}^{2}}{\mathrm{Nd}^{2}+\mathrm{Z}^{2} \mathrm{~S}^{2}}$

Keterangan :

$\mathrm{n} \quad=$ jumlah sampel

$\mathrm{Z} \quad=$ tingkat kepercayaan $(95 \%=1,96)$

$\mathrm{N} \quad=$ jumlah populasi

$\mathrm{d}=$ derajat penyimpangan $(5 \%=0,05)$

$\mathrm{S}^{2} \quad=$ varietas sampel $(5 \%=0,05)$

Perhitungan jumlah sampel petani ikan air tawar yang diperoleh adalah :

$\mathrm{n}=\frac{103(1,96)^{2}(0,05)}{103(0,05)^{2}+(1,96)^{2}(0,05)}$

$\mathrm{n}=\frac{19,78424}{0,44958}$

$\mathrm{n}=44,006$

$\mathrm{n}=44$ orang

Jumlah sampel yang diperoleh dalam penelitian ini adalah 44 responden. Penentuan jumlah sampel dari masing-masing desa dan Pokdakan dilakukan dengan menggunakan rumus alokasi proporsional sample sebagai berikut :

$\mathrm{ni}=\frac{\mathrm{Ni}}{\mathrm{N}} \times \mathrm{n}$.

Keterangan :

ni = Jumlah sampel menurut stratum

$\mathrm{Ni}=$ Jumlah populasi menurut stratum

$\mathrm{n} \quad=$ Jumlah sampel seluruhnya

$\mathrm{N}$ = Jumlah populasi menurut stratum

Jumlah sampel yang diambil dari Desa Lugusari adalah :

$\mathrm{n}_{\mathrm{i}}=\frac{43 \times 44}{103}=18,37=18$ orang 
Tabel 1. Sebaran responden petani ikan air tawar di Kecamatan Pagelaran, Kabupaten Pringsewu, 2017

\begin{tabular}{|c|c|c|c|c|c|}
\hline Kecamatan & Desa & Pokdakan & Usaha & $\begin{array}{c}\text { Jumlah Populasi } \\
\text { (Orang) }\end{array}$ & $\begin{array}{c}\text { Jumlah Sampel } \\
\text { (Orang) }\end{array}$ \\
\hline \multirow{8}{*}{ Pagelaran } & \multirow{4}{*}{ Pagelaran } & Mekar Jaya 2 & Pembenihan & 15 & 6 \\
\hline & & Maju Bersama & Pembesaran & 16 & 7 \\
\hline & & Mina Tani & Pembenihan dan Pembesaran & 16 & 7 \\
\hline & & Mekar Jaya & Pembenihan dan Pembesaran & 14 & 6 \\
\hline & \multirow{3}{*}{ Lugusari } & Pelita & Pembesaran & 13 & 6 \\
\hline & & Karya Mandiri & Pembesaran & 15 & 6 \\
\hline & & Muncul & Pembenihan dan Pembesaran & 14 & 6 \\
\hline & \multicolumn{2}{|c|}{ Jumlah } & & 103 & 44 \\
\hline
\end{tabular}

Jumlah sampel yang diambil dari Desa Pagelaran adalah :

$\mathrm{n}_{\mathrm{i}}=\frac{60 \times 44}{103}=25,63=26$ orang

Data yang dikumpulkan terdiri dari data primer yang diperoleh dari wawancara langsung dengan pembudidaya menggunakan kuisioner dan data sekunder diperoleh dari pengumpulan data dan studi literatur yang relevan melalui instansi terkait dengan penelitian. Metode analisis data yang digunakan adalah metode analisis kuantitatif untuk menjawab tujuan analisis sektor basis dan tingkat pendapatan usahatani.

Analisis Location Quotient (LQ) dilakukan untuk melihat sektor (komoditas) basis dari budidaya ikan air tawar di lokasi penelitian. Hasil perhitungan akan menunjukkan bahwa suatu komoditas tergolong basis atau tidak pada setiap daerah, yang ditandai dengan nilai LQ $>1$. Menurut Tarigan (2005), secara matematis perhitungan nilai LQ adalah :

$\mathrm{LQ}=\frac{\mathrm{ai} / \mathrm{pt}}{\mathrm{Ai} / \mathrm{Pt}}$

Keterangan :

$\mathrm{LQ}=$ Location Quotient

ai = Produksi (luas panen ) jenis komoditas $\mathrm{i}$ pada tingkat kecamatan

pt $=$ Produksi (luas panen) total perikanan air tawar pada tingkat kecamatan

$\mathrm{Ai}=$ Produksi (luas panen ) jenis komoditas $\mathrm{i}$ pada tingkat kabupaten

$\mathrm{Pt}=$ Produksi (luas panen) total perikanan air tawar pada tingkat kabupaten

Kriteria penilaian :

1. LQ > 1, maka komoditas adalah basis

2. $\mathrm{LQ}=1$, maka komoditas adalah non basis

3. $\mathrm{LQ}<1$, maka komoditas adalah non basis
Analisis usahatani dilakukan untuk mengetahui tingkat pendapatan usahatani ikan mas (komoditas basis utama) pada masing-masing fokus usaha (usaha pembenihan, usaha pembesaran, usaha pembenihan dan pembesaran). Penentuan tingkat pendapatan ini menggunakan perhitungan biaya total (TC), penerimaan, keuntungan, $\mathrm{R} / \mathrm{C}$, dan analisis BEP (Break Event Point).

\section{a. Biaya Produksi (Total Cost)}

Biaya produksi merupakan semua pengeluaran yang dilakukan oleh perusahaan yang terdiri dari biaya tetap dan biaya variabel untuk memperoleh faktor-faktor produksi dan bahanbahan mentah yang akan digunakan untuk memproduksi produk dari suatu perusahaan (Suratiyah 2008).

$\mathrm{TC}=\mathrm{TFC}+\mathrm{TV}$

Keterangan :

1. $\mathrm{TC}=$ Biaya total (Total Cost)

2. TFC = Biaya tetap total (Total Fixed Cost)

3. TVC = Biaya variabel total (Total Variable Cost)

\section{b. Penerimaan Usaha (Total Revenue)}

Menurut Suratiyah (2008) penerimaan usaha adalah jumlah produksi (output) dikalikan dengan harga produk (Price) dengan menggunakan satuan rupiah. Secara matematis penerimaan usahatani/budidaya dapat dirumuskan sebagai berikut :

$\mathrm{TR}=\mathrm{Y} . \mathrm{Py}$

Keterangan:

$\mathrm{TR}=$ Total Penerimaan

$\mathrm{Y}=$ Produksi yang diperoleh dari suatu usahatani

Py = Harga produksi 
c. Keuntungan/Pendapatan

Pendapatan adalah selisih antara total penerimaan dengan total biaya yang dikeluarkan dalam satu periode produksi usaha (Suratiyah 2008).

$\pi=\mathrm{TR}-\mathrm{TC}$

$\pi=(\mathrm{P} . \mathrm{Q})-(\mathrm{TFC}+\mathrm{TVC})$

Keterangan :

$\pi=$ Pendapatan $/$ Keuntungan

$\mathrm{TR}=$ Total Penerimaan (Total Revenue)

$\mathrm{TC}=$ Total Biaya $($ Total Cost $)$

$\mathrm{P} \quad=$ Harga (Price)

$\mathrm{Q}=$ Quantitas Produk (Quantity)

TFC = Biaya tetap total (Total Fixed Cost)

TVC = Biaya variabel total (Total Variable Cost)

\section{d. R/C Ratio}

$\mathrm{R} / \mathrm{C}$ ratio adalah penerimaan atas biaya yang menunjukan besarnya penerimaan yang akan diperoleh dari setiap rupiah yang dikeluarkan dalam produksi usaha budidaya ikan air tawar (Suratiyah 2008).

$$
\mathrm{R} / \mathrm{C} \text { Ratio }=\mathrm{TR} / \mathrm{TC}
$$

Keterangan:

$\mathrm{R} / \mathrm{C}=$ Nisbah penerimaan dan biaya

$\mathrm{TR}=$ Penerimaan total

$\mathrm{TC}=$ Biaya total yang dikeluarkan

Kriteria penilaian :

1. $\mathrm{R} / \mathrm{C}>1$, maka usahatani layak

2. $\mathrm{R} / \mathrm{C}=1$, maka usahatani titik impas

3. $\mathrm{R} / \mathrm{C}<1$, maka usahatani tidak layak

\section{e. Analisis Break Event Point (BEP)}

Analisis BEP digunakan untuk mencari batas minimum volume penjualan dan harga jual ikan mas agar dapat menutupi biaya yang dikeluarkan dalam usaha budidaya. Pada penelitian ini, perhitungan BEP yang dilakukan meliputi BEP unit ikan dan BEP harga atau sama dengan biaya rata-rata per unit, dalam istilah ekonomi mikro disebut harga pokok, sehingga jika produk dijual pada harga ini, maka mencapai titik impas. Perhitungan BEP menurut Suratiyah (2008), yaitu:

$\mathrm{BEP}$ unit $=\frac{\mathrm{TFC}}{\mathrm{P}-\mathrm{VC}}$
BEP harga $=\frac{\mathrm{TC}}{\mathrm{Y}}$

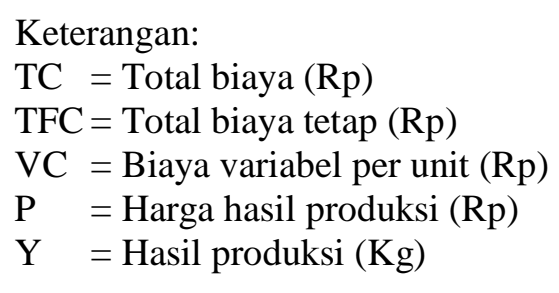

\section{HASIL DAN PEMBAHASAN}

\section{Karakteristik Responden}

Pembudidaya ikan air tawar yang diamati pada penelitian ini adalah pembudidaya yang berfokus pada usaha pembenihan (6 pembudidaya), usaha pembesaran (19 pembudidaya) serta usaha pembenihan dan pembesaran ikan air tawar (19 pembudidaya). Karakteristik pembudidaya ikan air tawar yang diamati, yaitu status keanggotaan Pokdakan, umur, pengalaman usaha, tingkat pendidikan dan tanggungan keluarga. Beberapa karakteristik tersebut diharapkan dapat menggambarkan kondisi responden di lokasi penelitian.

Status keanggotaan responden dalam Pokdakan adalah sebagai pengurus inti (21 petani) dan anggota biasa (23 petani). Rentang usia pembudidaya adalah 21 sampai lebih dari 41 tahun, dengan mayoritas pembudidaya (54,55 persen) berusia lebih dari atau sama dengan 41 tahun. Tingkat pendidikan pembudidaya sudah tergolong baik, yaitu lebih dari 50 persen sudah mengenyam pendidikan wajib sembilan tahun. Pengalaman budidaya berkisar antara 7 sampai dengan 45 tahun, dengan mayoritas berada pada kisaran 11-20 tahun $(54,55$ persen). Tanggungan keluarga petani berkisar antara nol hingga lima orang.

Sebagian pembudidaya menjadikan usaha budidaya ikan air tawar sebagai pekerjaan utama, namun adapula yang menjadikannya sebagai sampingan saja. Luas kolam yang diusahakan berkisar antara $800-12.000 \mathrm{~m}^{2}$, dengan rata-rata luas kolam untuk usaha pembenihan sebesar $2.583,33 \mathrm{~m}^{2}$, usaha pembesaran sebesar 1.796,05 $\mathrm{m}^{2}$, serta usaha pembenihan dan pembesaran sebesar $3.689,47 \mathrm{~m}^{2}$. Berdasarkan hasil penelitian status kepemilikan kolam yang ada di daerah penelitian terdiri dari tiga kategori, yaitu milik pribadi, sewa, serta kepemilikan pribadi dan sewa. Secara umum biaya sewa lahan (kolam) per 2.500 $\mathrm{m}^{2}$ per tahun adalah Rp5.000.000,00 dan bervariasi bergantung dengan kondisi dan lokasi kolam. 


\section{Analisis Location Quotient (LQ)}

Penelitian ini menggunakan analisis LQ untuk menjawab tujuan pertama, yaitu analisis sektor basis (komoditas unggulan) pada budidaya ikan air tawar. Analisis LQ dilakukan pada lima komoditas ikan air tawar, yaitu ikan mas, lele, gurame, nila dan patin dengan pertimbangan bahwa, kelima komoditas ini adalah komoditas yang paling banyak dibudidayakan di lokasi penelitian. Perhitungan nilai LQ dilakukan dengan mengolah data produksi dan luas lahan budidaya dari tahun 2012 - 2016 (lima tahun terakhir). Rata-rata nilai LQ usahatani ikan air tawar di Kecamatan Pagelaran, Kabupaten Pringsewu tahun 2012-2016 dapat dilihat pada Tabel 2.

Berdasarkan hasil perhitungan pada Tabel 2, maka komoditas basis perikanan air tawar adalah ikan mas dengan nilai 1,18 dan ikan patin dengan nilai 1,03. Kedua komoditas ini adalah komoditas basis dari sektor perikanan air tawar yang mampu memenuhi kebutuhan dalam dan luar Kecamatan Pagelaran, serta memiliki keunggulan komparatif yang lebih besar dibandingkan ikan lele, gurame dan nila. Menurut Tarigan (2005) semakin tinggi nilai LQ, maka menunjukkan semakin tinggi pula potensi (keunggulan) komoditas tersebut. Berdasarkan hal tersebut, maka dapat disimpulkan bahwa ikan mas merupakan komoditas ikan air tawar yang memiliki keunggulan komparatif terbesar dan merupakan komoditas unggulan utama perikanan air tawar di Kecamatan Pagelaran, Kabupaten Pringsewu.

\section{Analisis Pendapatan Budidaya Ikan Air Tawar}

Teori analisis usahatani digunakan untuk menjawab tujuan kedua, yaitu tingkat pendapatan pada budidaya ikan air tawar. Analisis pendapatan dilakukan pada budidaya ikan mas yang merupakan komoditas basis (unggulan) utama di Kecamatan Pagelaran, Kabupaten Pringsewu. Analisis dilakukan terhadap tiga fokus usaha budidaya, yaitu usaha pembenihan, usaha pembesaran, serta usaha pembenihan dan pembesaran ikan air tawar di lokasi penelitian. Analisis pendapatan yang dilakukan meliputi biaya total (TC), total penerimaan (TR), keuntungan $(\pi)$, R/Cratio, dan BEP (Break Event Point). Sebaran analisis pendapatan, dan R/C Ratio pada ketiga fokus usaha budidaya ikan mas dapat dilihat pada Tabel 3.

Berdasarkan Tabel 3, tingkat pendapatan atas biaya total tertinggi per $1.000 \mathrm{~m}^{2}$ per bulan adalah fokus usaha pembesaran dengan tingkat pendapatan sebesar Rp1.556.440,29/bulan. Posisi kedua, yaitu usaha pembenihan dan pembesaran dengan tingkat pendapatan sebesar Rp1.331,345,11/bulan. Posisi ketiga, yaitu usaha pembenihan dengan tingkat pendapatan sebesar Rp999.341,19/bulan. Usaha pembesaran menempati posisi tertinggi dikarenakan usaha pembesaran menggunakan bibit dengan ukuran, umur, dan kualitas yang baik sehingga resiko kematian lebih kecil, namun asupan pakan lebih besar sehingga modal yang dibutuhkan lebih besar.

Berdasarkan nilai $\mathrm{R} / \mathrm{C}$, usaha pembenihan memperoleh nilai tertinggi dengan nilai $\mathrm{R} / \mathrm{C}$ atas biaya tunai sebesar 2,81 yang berarti bahwa untuk setiap Rp1,00 biaya tunai yang diinvestasikan pada kegiatan usaha pembenihan akan memberikan penerimaan sebesar Rp2,81. Nilai R/C atas biaya total sebesar 1,56, yang berarti bahwa untuk setiap Rp1,00 biaya total yang diinvestasikan pada kegiatan usaha pembenihan akan memberikan penerimaan sebesar Rp1,56.

Posisi kedua adalah usaha pembesaran dan pembenihan dengan nilai $\mathrm{R} / \mathrm{C}$ atas biaya tunai sebesar 1,92, yang berarti bahwa untuk setiap Rp1,00 biaya tunai yang diinvestasikan pada kegiatan usaha pembenihan dan pembesaran akan memberikan penerimaan sebesar Rp1,92. Nilai $\mathrm{R} / \mathrm{C}$ atas biaya total sebesar 1,51 , yang berarti bahwa untuk setiap Rp1,00 biaya total yang diinvestasikan pada kegiatan usaha pembenihan dan pembesaran akan memberikan penerimaan sebesar Rp 1,51.

Posisi ketiga adalah usaha pembesaran dengan nilai $\mathrm{R} / \mathrm{C}$ atas biaya tunai sebesar 1,64 yang berarti bahwa untuk setiap Rp1,00 biaya tunai yang diinvestasikan pada kegiatan usaha pembesaran akan memberikan penerimaan sebesar Rp1,64. Nilai R/C atas biaya total sebesar 1,37, yang berarti bahwa untuk setiap Rp1,00 biaya total yang diinvestasikan pada kegiatan usaha pembesaran akan memberikan penerimaan sebesar Rp1,37.

Tabel 2. Rata-rata nilai LQ usahatani ikan air tawar di Kecamatan Pagelaran, Kabupaten Pringsewu tahun 2012-2016

\begin{tabular}{|c|c|c|c|c|c|c|c|c|}
\hline \multirow{2}{*}{ No } & Jenis & \multicolumn{5}{|c|}{ Nilai LQ } & \multirow{2}{*}{ Jumlah } & \multirow{2}{*}{$\begin{array}{l}\text { Rata-rata } \\
\text { Nilai LQ }\end{array}$} \\
\hline & Ikan & 2012 & 2013 & 2014 & 2015 & 2016 & & \\
\hline 1 & Mas & 1,26 & 1,18 & 1,07 & 1,17 & 1,20 & 5,88 & 1,18 \\
\hline 2 & Lele & 0,91 & 1,01 & 1,01 & 1,01 & 0,98 & 4,92 & 0,98 \\
\hline 3 & Patin & 1,01 & 1,01 & 1,02 & 1,05 & 1,08 & 5,16 & 1,03 \\
\hline 4 & Gurame & 0,58 & 0,58 & 0,57 & 0,57 & 0,64 & 2,94 & 0,59 \\
\hline 5 & Nila & 1,00 & 0,86 & 1,04 & 0,85 & 0,88 & 4,63 & 0,93 \\
\hline
\end{tabular}


Tabel 3. Analisis pendapatan pada tiga fokus usaha ikan mas per $1.000 \mathrm{~m}^{2}$ per bulan di Kecamata Pagelaran, Kabupaten Pringsewu, tahun 2017

\begin{tabular}{|c|c|c|c|c|c|c|c|c|c|}
\hline \multirow{2}{*}{ No } & \multirow{2}{*}{ Uraian } & \multirow{2}{*}{ Satuan } & \multirow{2}{*}{$\begin{array}{c}\text { Harga } \\
\text { (Rp) }\end{array}$} & \multicolumn{2}{|c|}{ Pembenihan } & \multicolumn{2}{|c|}{ Pembesaran } & \multicolumn{2}{|c|}{ Pembenihan \& Pembesaran } \\
\hline & & & & Jumlah & Nilai & Jumlah & Nilai & Jumlah & Nilai \\
\hline \multicolumn{10}{|c|}{1 Penerimaan } \\
\hline & A. Ikan konsumsi & $\mathrm{Kg}$ & $21.500,00$ & & & 804,98 & 17.307.131,59 & 616,76 & $13.260 .391,27$ \\
\hline \multicolumn{10}{|c|}{ B. Bibit } \\
\hline & Gelasan & Gelas & $20.000,00$ & 3,23 & $64.516,21$ & & & 2,40 & $47.931,57$ \\
\hline & $(3-5)$ & Ekor & 90,00 & $1.483,87$ & $133.548,56$ & & & $3.352,36$ & $301.712,14$ \\
\hline & $(4-6)$ & Ekor & 110,00 & $5.483,88$ & $603.226,58$ & & & $7.860,21$ & $864.622,83$ \\
\hline & $(5-7)$ & Ekor & 125,00 & $21.354,87$ & $2.669 .358,28$ & & & $18.202,59$ & $2.275 .323,24$ \\
\hline & $(7-8)$ & Ekor & 150,00 & $4.129,04$ & $619.355,64$ & & & $4.636,24$ & $695.435,79$ \\
\hline & $(8-10)$ & Ekor & 175,00 & 483,87 & $84.677,53$ & & & $1.854,50$ & $324.536,70$ \\
\hline & Total penerimaan & $\mathrm{Rp}$ & & & $4.174 .682,81$ & & $17.307 .131,59$ & & $17.769 .953,55$ \\
\hline \multicolumn{10}{|c|}{2 Biaya produksi } \\
\hline & Biaya tunai & $\mathrm{Rp}$ & & & $1.485 .600,30$ & & $10.564 .094,97$ & & $9.259 .435,84$ \\
\hline & Biaya total & $\mathrm{Rp}$ & & & $2.675 .671,02$ & & $12.637 .810,70$ & & $11.778 .900,56$ \\
\hline \multicolumn{10}{|c|}{3 Pendapatan } \\
\hline & Periode Produksi & Bulan & & & 1,50 & & 3,00 & & 4,50 \\
\hline & Atas biaya tunai (Periode) & $\mathrm{Rp}$ & & & $2.689 .082,50$ & & $6.743 .036,62$ & & $8.510 .517,71$ \\
\hline & Atas biaya total (Periode) & $\mathrm{Rp}$ & & & $1.499 .011,79$ & & $4.669 .320,88$ & & $5.991 .052,99$ \\
\hline & Atas biaya tunai (bulan) & $\mathrm{Rp}$ & & & $1.792 .721,67$ & & $2.247 .678,87$ & & $1.891 .226,16$ \\
\hline & Atas biaya total (bulan) & $\mathrm{Rp}$ & & & $999.341,19$ & & $1.556 .440,29$ & & $1.331,345,11$ \\
\hline \multicolumn{10}{|c|}{$4 \mathrm{R} / \mathrm{C}$} \\
\hline & Atas biaya tunai & $\%$ & & & 2,81 & & 1,64 & & 1,92 \\
\hline & Atas biaya total & $\%$ & & & 1,56 & & 1,37 & & 1,51 \\
\hline
\end{tabular}

Berdasarkan nilai $\mathrm{R} / \mathrm{C}$ ratio yang diperoleh ketiga fokus usaha budidaya, dapat disimpulkan bahwa ketiga fokus usaha tersebut layak untuk dijalankan karena sejalan dengan hasil penelitian dari Perdana (2015) yang menyatakan bahwa budidaya ikan mas memiliki nilai $\mathrm{R} / \mathrm{C}>1$. Hasil penelitian ini juga sejalan dengan penelitian Yuwani, Irham, dan Jamhari (2014), yang menyatakan bahwa berdasarkan nilai $\mathrm{R} / \mathrm{C}$ usaha yang paling menguntungkan adalah pembenihan karena memiliki waktu produksi dan biaya pakan yang lebih sedikit, namun tingkat pendapatan tertinggi dimiliki oleh usaha pembesaran.

\section{Analisis Break Event Point (BEP)}

Break Even Point (BEP) adalah kondisi impas suatu usaha, karena hasil penjualan produk besarnya sama dengan biaya yang dikeluarkan selama produksi berlangsung. Perhitungan BEP terdiri dari BEP unit dan BEP harga atau rupiah yang didasarkan pada unit ikan dan harga ikan. Perhitungan BEP pada usahatani ikan mas digunakan untuk menentukan batas minimum kuantitas (unit) dan harga jual produk yang dihasilkan agar usaha budidaya ikan mas yang dijalankan tidak mengalami kerugian. Sebaran nilai BEP unit dan harga pada tiga fokus usaha budidaya ikan mas di Kecamatan Pagelaran, Kabupaten Pringsewu, tahun 2017 dapat dilihat pada Tabel 4.
Berdasarkan data pada Tabel 4 diketahui bahwa usaha pembenihan perlu memproduksi $26.857,80$ ekor bibit dengan harga jual Rp73,99/ekor untuk mencapai titik impas. Usaha pembesaran perlu memproduksi 263,45 $\mathrm{kg}$ ikan ukuran konsumsi dengan harga Rp15.699,48/kg, untuk mencapai titik impas, serta usaha pembenihan dan pembesaran perlu memproduksi 900,70kg ikan dengan harga jual Rp19.097,96/kg agar usaha yang dijalankan mencapai titik impas

Tabel 4. Sebaran nilai BEP per periode produksi pada tiga fokus usaha budidaya ikan mas di Kecamatan Pagelaran, Kabupaten Pringsewu, tahun 2017

\begin{tabular}{llcr}
\hline No. Fokus Usaha & \multicolumn{1}{c}{ Uraian } & Satuan & \multicolumn{1}{c}{ Nilai } \\
\hline 1. Pembenihan & BEP Unit & Ekor & $26.857,80$ \\
& BEP Harga & $\mathrm{Rp}$ & 73,99 \\
\hline 2. Pembesaran & BEP Unit & $\mathrm{Kg}$ & $1.580,71$ \\
& BEP Harga & $\mathrm{Rp}$ & $2.616,58$ \\
\hline 3. Pembenihan dan & BEP Unit & $\mathrm{Kg}$ & 900,70 \\
pembesaran & BEP Harga & $\mathrm{Rp}$ & $19.097,96$ \\
\hline
\end{tabular}




\section{KESIMPULAN}

Komoditas basis pada usahatani ikan air tawar di Kecamatan Pagelaran, Kabupaten Pringsewu adalah komoditas ikan mas dengan rata-rata nilai LQ sebesar 1,18 dan ikan patin dengan rata-rata nilai LQ sebesar 1,03. Tingkat pendapatan per $1.000 \mathrm{~m}^{2}$ per bulan pada usaha budidaya ikan mas, yaitu usaha pembenihan dengan nilai pendapatan Rp999.341,19, usaha pembesaran dengan nilai pendapatan Rp1.556.440,29, serta usaha pembenihan dan pembesaran dengan nilai pendapatan Rp1.198.210,60.

\section{DAFTAR PUSTAKA}

BPS [Badan Pusat Statistik]. 2016. Laju Pertumbuhan Kumulatif PDB Menurut Lapangan Pekerjaan. BPS. https://bps.go.id/ subject/11/produkdomestikbrutolapanganusah a. html\#subjekViewTab3. [8 Februari 2017].

BPS [Badan Pusat Statistik] Kabupaten Pringsewu. 2017. Kabupaten Pringsewu Dalam Angka. BPS Kabupaten Pringsewu. https://pringsewu kab.bps.go.id/publication/2018/01/03/86ce50d baf9af37bd6d31737/statistik-kesejahteraan-ra kyat-kabupaten-pringsewu-2016.html. [8 Februari 2017].
Dinas Perikanan dan Kelautan Provinsi Lampung. 2016. Laporan Tahunan Statistik Perikanan Budidaya. Dinas Perikanan dan Kelautan Provinsi Lampung Bandar Lampung.

Dinas Peternakan dan Perikanan Kabupaten Pringsewu. 2016. Laporan Tahunan Statistik Perikanan Budidaya. Dinas Peternakan dan Perikanan Kabupaten Pringsewu. Kabupaten Pringsewu.

Perdana APS. 2015. Analisis Pendapatan dan Resiko Usahatani Ikan Lele dan Ikan Mas di Kecamatan Pagelaran Kabupaten Pringsewu. Skripsi. Universitas Lampung. Bandar Lampung.

Sugiarto D, Sunaryanto S, dan Oetomo DS.2003. Teknik Sampling. Gramedia PustakaUtama. Jakarta.

Suratiyah K. 2008. Ilmu Usahatani. Penebar Swadaya. Jakarta.

Tarigan R. 2005. Ekonomi Regional Teori dan Aplikasi Edisi Revisi. PT Bumi Aksara. Jakarta.

Yuwani SH, Irham, dan Jamhari. 2014. Analisis kelayakan dan strategi pengembangan usaha budidaya ikan air tawar di kabupaten sleman. Agro Ekonomi : 25 (2): 135-143. https:// jurnal.ugm.ac.id/jae/article/view/17191/11235 [8 Februari 2017]. 